\title{
AUTOMATIC TEACHING OF A ROBOTIC REMOTE LASER 3D PROCESSING SYSTEM BASED ON LASER-TRIANGULATION PROFILOMETRY
}

\author{
Matija Jezeršsek, Matjaž Kos, Hubert Kosler, Janez, Možina
}

Original scientific paper

One of the key challenges in robotic remote laser 3D processing (RL3DP) is to achieve high accuracy for the laser's working trajectory relative to the features of the workpiece. This paper presents a novel RL3DP system with an automatic 3D teaching functionality for a precise and rapid determination of the working trajectory which comprises a robot manipulator, 3D scanning head, fibre laser and an off-axis positioned camera. The 3D measurement is based on laser triangulation with laser-stripe illumination using the laser's pilot beam and scanning head. The experimental results show that the system has a precision better than $70 \mu \mathrm{m}$ and $120 \mu \mathrm{m}$ along lateral and vertical direction respectively inside the measuring range of $100 \times 100 \mathrm{~mm}$. The teaching time is 30-times shorter compared to a visual teaching procedure. Therefore, such a system can lead to large cost reductions for modern production lines that have constant changes to the products' geometries and functionalities.

Keywords: edge detection; laser triangulation; remote laser processing; robot teaching; three-dimensional measurement

Automatsko učenje robotskih laserskih daljinskih 3D obradnih sustava na osnovu laserske triangulacije

Izvorni znanstveni članak Jedan od bitnih izazova u daljinskoj laserskoj 3D obradi (RL3DP) je postizanje visoke točnosti jer laser radi po rubovima predmeta koji obrađuje. Ovaj rad prikazuje novi RL3DP sustav s automatskom 3D nastavnom funkcionalnošću radi točnog i brzog određivanja prijenosa detektiranih rubova koje obrađuje robot sa 3D skenerom, fiber laserom i izvan aksijalno pozicioniranom kamerom. 3D skeniranje se bazira na laserskoj triangulaciji sa pilotskom laserskom trakom. Eksperimentalni rezultati pokazuju da sustav ima preciznost bolju od $70 \mu \mathrm{m}$ i $120 \mu \mathrm{m}$ u bočnom i vertikalnom smjeru u mjernom području od $100 \times 100 \mathrm{~mm}$. Vrijeme učenja je 30-puta kraće u odnosu na vizualni postupak. Stoga, takav sustav može značajno smanjiti troškove obrade sa modernim proizvodnim sistemima koji se moraju prilagođavati stalnim promjenama geometrije i funkcionalnosti proizvoda.

Ključne riječi: daljinska laserska obrada; davanje uputa robotu; detekcija rubova; laserska triangulacija; trodimenzijska mjerenja

\section{Introduction}

The increasing use of laser-processing technologies across a broad spectrum of applications is mainly attributed to the ability to produce an extremely precise and concentrated laser energy input $[1 \div 3]$. The maximum working speed can be determined from a scanning head with two galvanometer-driven mirrors that steer the laser beam in lateral directions. Such a configuration has a much smaller inertial mass than the conventional movement provided by a robot arm only. The combination of a robot and a scanning head, the so-called remote laser three-dimensional processing (RL3DP) systems, is becoming widespread in the automotive and electronics industries, particularly in welding, cutting and surface-structuring applications $[4 \div 11]$ due to a significant reduction in the non-productive positioning times.

One of the key challenges related to RL3DP is the required accuracy of the laser's working trajectory relative to the features of the workpiece, such as edges, seams, holes or grooves [3]. The tolerance is typically a fraction of the focus diameter in the lateral direction and a fraction of the Rayleigh length (focus depth) in the axial direction [12]. Since modern fibre or disk lasers have a high-quality beam $[13,14]$, the corresponding positional accuracy must typically be smaller than $0,1 \mathrm{~mm}$. Therefore, conventional visual robot teaching (with the naked eye) is both inaccurate and time consuming.

A number of automated methods have been developed for faster and more accurate working-trajectory determinations. These are based on inductive, capacitive, visual (2D) and triangulation (3D) principles [16]. A coaxial vision system can determine the positions of the features in a lateral direction with an acceptable precision $[17,18]$, but it cannot determine the position in a vertical direction. In contrast, the laser-triangulation sensors make it possible to determine the features, not only in the lateral direction, but also in a direction normal to the surface $[19 \div 23]$. They consist of a laser-stripe projector and a camera where the projector illuminates the landmark region with a light plane and the camera records this region from a different angle. The drawback of these sensors is that only the profile at some fixed, stand-off distance relative to the welding head is measured. Therefore, the relative position of the sensor with respect to the laser head must be calibrated and taken into account. A more flexible solution is described in [24], where the laser beam, which is guided with a scanning head, is first used for the laser-stripe projection during a $3 \mathrm{D}$ measurement and then for the marking. But the system lacks flexibility since it does not include a robot manipulator that allows the processing of geometrically highly complex workpieces.

This paper presents a novel system for remote laser $3 \mathrm{D}$ processing with an integrated 3D teaching functionality for a rapid and precise determination of the laser's working trajectory. The system, as described in Section 2, is composed of a robot manipulator, a 3D scanning head, a fibre laser and an additional off-axis camera. The 3D surface measurement is based on a laser triangulation with a laser-stripe illumination using the laser's pilot beam, which is otherwise used for the visual teaching procedure. The laser light plane is generated with the scanning head by the rapid deflection of the laser pilot beam. The workpiece's edges are determined from the measured profiles after the 3D measurement in order to generate the $3 \mathrm{D}$ laser's working trajectory. The 
system's calibration is described in Section 3, where a precise transformation between the coordinate systems of the camera, the scanning head and the robot's base frame are determined. The experimental results are applied to two characteristic workpieces with overlap seam geometry in Section 4, and the conclusions are drawn in Section 5.

\section{System setup and algorithms}

The proposed automatic 3D teaching method is composed of four main steps: (i) 3D measurement of the workpiece; (ii) detection of the working trajectory; (iii) post-processing of the working trajectory; and (iv) actual laser processing. This section describes the hardware and the algorithms for the above-mentioned steps.

\subsection{Hardware}

The system is shown in Fig. 1. The high-power laser (IPG, model YLR-400-AC, $400 \mathrm{~W}$, continuous-wave, wavelength $1070 \mathrm{~nm}$ ) is used in the system for the welding, cutting and marking applications. Its light is guided through the optical fibre to the 3D scanning head (HighYAG, model RLSK), which is held by the 6-axis robot (Yaskawa, model MC2000). The 3D scanning head consists of adaptive focusing optics (focus movement along the laser beam's axis) and two galvanometer-driven mirrors that steer the laser beam along the $\mathrm{X}$ and $\mathrm{Y}$ axes of the scanning head frame (SHF). The working volume of the scanning head is $200 \times 300 \times 200 \mathrm{~mm}$ (width $\times$ length $\times$ height) at a distance of $600 \mathrm{~mm}$ from the last optical surface. A camera (PointGrey, model FL3-U3-13Y3M-C, $1280 \times 1024$ pix, $150 \mathrm{fps}$, sensor size $\left.1 / 2^{\prime \prime}\right)$ is fixed off-axis relative to the scanning head (triangulation angle is $20^{\circ}$ ). The imaging lens, with a focal length of $35 \mathrm{~mm}$, includes a narrow band interference filter (central wavelength is $660 \mathrm{~nm}$, FWHM spectral width is $10 \mathrm{~nm}$ ) for a contrast improvement between the laser stripe and the background, and an additional filter for blocking the high-power laser light (heat-absorbing glass, KG-5) to protect the camera's sensor against damage. The laser focus (the pilot beam during a $3 \mathrm{D}$ measurement and the working beam during laser processing) is guided in 3D space by the synchronized movement of the robot arm and the scanning head. The synchronization is carried out by the robot controller, which outputs a trigger signal to the personal computer (PC), which further controls the scanning head by sending coordinates in a TF with 1-ms time intervals $(\Delta t)$ using the controller-area-network (CAN) protocol.

\subsection{Measurements of the workpiece's 3D shape}

The measurements of the workpiece's 3D shape are based on the laser-triangulation principle where the camera acquires images of the surface that is illuminated by a laser light plane from a different angle [15, 25]. In such a configuration the laser stripe on the acquired image is distorted according to the surface of the measured section. The laser light plane is generated with the scanning head by the rapid deflection of the laser pilot beam (wavelength $660 \mathrm{~nm}$ ) along the $Y$ axis relative to the
SHF. The pilot beam's oscillation is synchronized with the camera's acquisition speed (40 profiles/s).

The processing area is measured by moving the scanning head along the scanning trajectory, as shown in Fig. 1. The linear trajectory is manually determined by selecting the starting and final points (see $\mathrm{P}_{\text {start }}$ and $\mathrm{P}_{\text {end }}$ on Fig. 1). Otherwise, if the workpiece's geometry is more complex, an arc-shaped or polygonal trajectory can be used. The typical scanning speed during a 3D measurement is $10 \mathrm{~mm} / \mathrm{s}$.

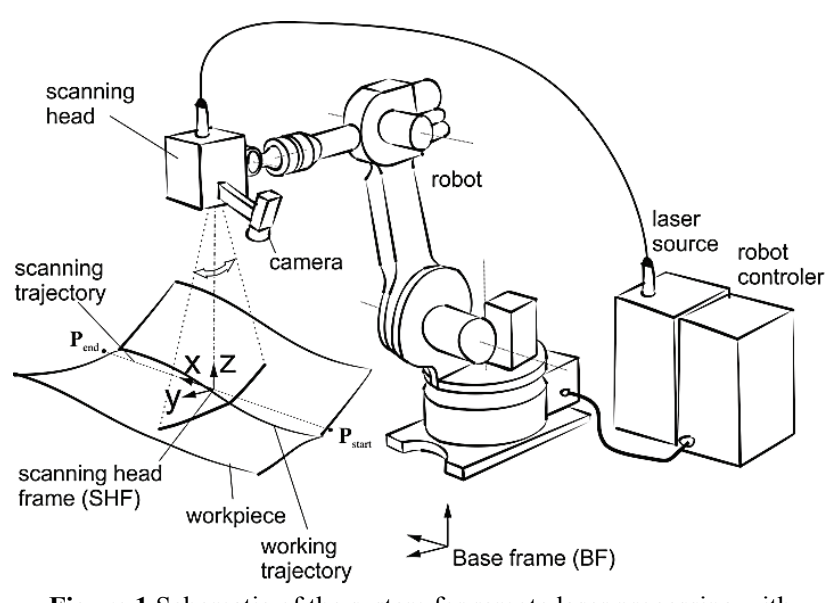

Figure 1 Schematic of the system for remote laser processing with automatic $3 \mathrm{D}$ teaching of the working trajectory

\subsection{Working-trajectory detection}

The precise detection of the laser's working trajectory in 3D space is particularly important in the case of a buttor fillet-weld geometry, where misalignment between the laser beam and the seam leads to a low-strength weld. Therefore, the working-trajectory detection in the case of a continuous welding application is presented in this subsection.

The algorithm for the 3D working-trajectory detection from the measured 3D shape is shown in Fig. 2. The input data is a matrix-arranged point-cloud with four values for each point $(X, Y$ and $Z$ coordinates and the intensity of the laser stripe at the measured points). Every row of the matrix represents one measured profile. The trajectory detection begins at the first profile and iterates to the last one. For each profile a peak or valley is detected with three types of signals. The first detection is based on the profile's intensity change. The second is based on profile's height change (first derivative of $Z$ along the $Y$ axis $-Z_{Y}$ ) and the third is based on the profile's direction change (second derivative of $Z$ along the $Y$ axis $-Z_{Y Y}$ ). In all three cases a peak-detection routine based on the calculation of the second derivative is used [26].

Since multiple peak or valley points can appear on each profile, the most relevant is selected by calculating its strength $(S)$, where combination of all three signals is taken into account:

$$
S_{i}=\sqrt{\left[\frac{I_{i}-I_{\text {avg }}}{\Delta I_{\text {thresh }}}\right]^{2}+\left[\frac{Z_{Y_{i}}}{Z_{Y_{\text {thresh }}}}\right]^{2}+\left[\frac{Z_{Y Y_{i}}}{Z_{Y Y_{\text {thresh }}}}\right]^{2}}
$$


The index $i$ denotes a consecutive point on the current profile, $I$ and $I_{\text {avg }}$ are the intensities at the detected point and the average intensity of the entire profile, respectively. $\Delta I_{\text {thresh }}$ is an intensity threshold value. $Z_{Y_{i}}$ is the first derivative of the surface height along the $Y$ axis at the $i^{\text {th }}$ point and $Z_{Y_{\text {thresh }}}$ is the corresponding threshold value. Similarly, $Z_{Y Y_{i}}$ is the second derivative of the surface height along the $Y$ axis at the $i^{\text {th }}$ point and $Z_{Y Y_{\text {thresh }}}$ is the corresponding threshold value.

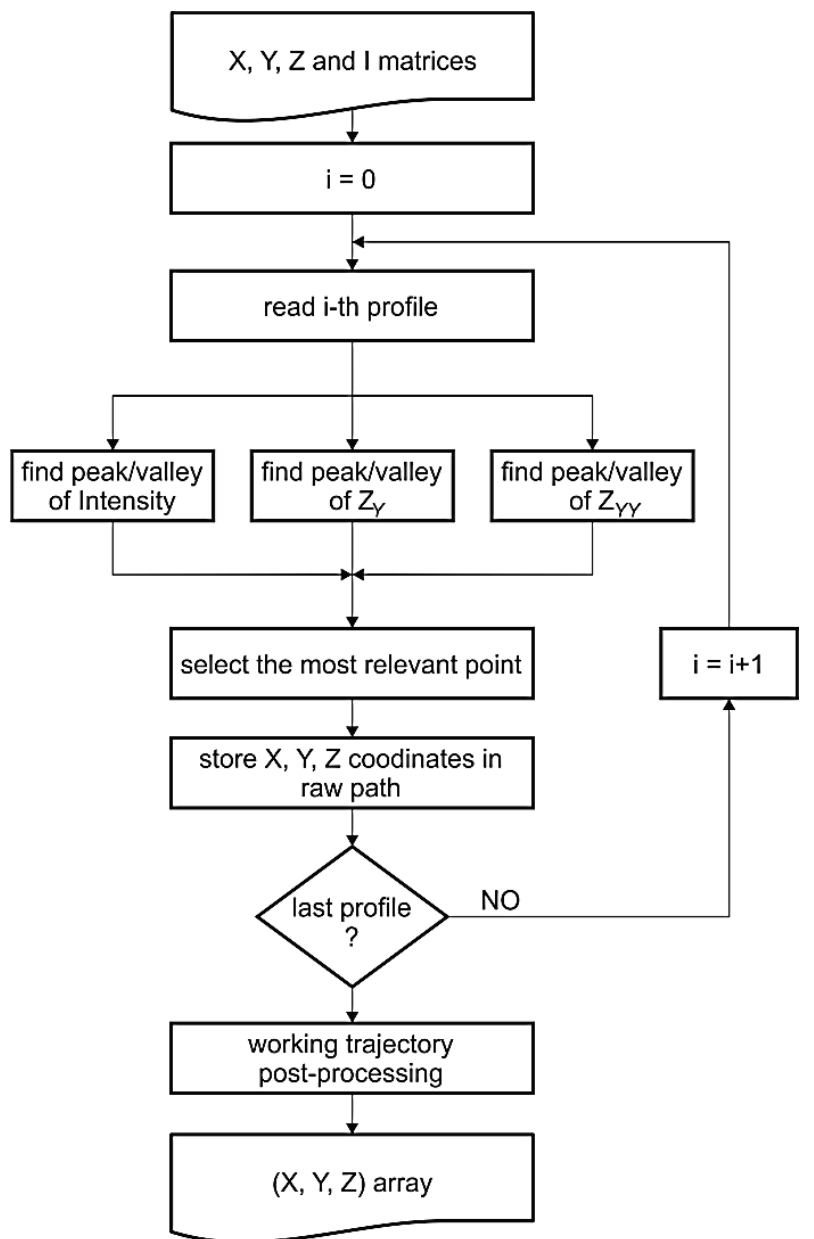

Figure 2 Algorithm for 3D working-trajectory detection

The most relevant point on the current profile is the one that is the closest to the point found on the previous profile, and with strength greater than $1\left(S_{i}>1\right)$.
In the case of the first profile, the distances are calculated according to the point $\mathrm{P}_{\text {start }}$. Therefore, the operator must pick the starting point closer to the actual starting point of the edge contour than to any other geometric feature. The threshold values $\Delta I_{\text {thresh }}, Z_{Y_{\text {thresh }}}$ and $Z_{Y Y_{\text {thresh }}}$ in equation 1 depend on the geometry of the edge that needs to be determined. Tab. 1 shows typical geometries and the corresponding threshold values.

Using the described algorithm a single point is extracted from consecutive profiles. Their coordinates $(X$, $Y$ and $Z$ ) in the base frame (BF) are stored in a point array, which represents the raw data of the working trajectory. Raw data implies that some error points (outliers) might occur and that the point-to-point distance is equal along the scanning trajectory, which means that the working speed depends on the working-trajectory curvature. These two corrections are made in the next step - postprocessing of the working trajectory.

Table 1 Some edge geometries and the corresponding threshold values $\Delta I_{\text {thresh }}, Z_{Y_{\text {thresh }}}$ and $Z_{Y Y_{\text {thresh }}}$ used in Eq. (1) for the calculation of

\begin{tabular}{|c|c|c|c|c|}
\hline Geometry & $\begin{array}{c}\text { Edge } \\
\text { name }\end{array}$ & $\begin{array}{c}\Delta I_{\text {thresh }} \\
(-)\end{array}$ & $\begin{array}{c}Z_{Y_{\text {thresh }}} \\
(-)\end{array}$ & $\begin{array}{c}Z_{Y Y_{\text {thresh }}} \\
\left(\mathrm{mm}^{-1}\right)\end{array}$ \\
\hline & $\begin{array}{c}\text { Butt- } \\
\text { weld }\end{array}$ & 20 & 0,5 & 1 \\
\hline & Overlap & 20 & 1 & Infinity \\
\hline
\end{tabular}

\subsection{Working-trajectory post-processing}

The working-trajectory post-processing is composed of two steps: filtering and interpolation. First, the outliers are removed using a median filter for the $Y$ and $Z$ coordinates [26], where a typical filter width is 3 points. The points where the differences between the original and the filtered $Z$ coordinates are greater than the threshold value (typically $0,25 \mathrm{~mm}$ ) are replaced by the filtered one.

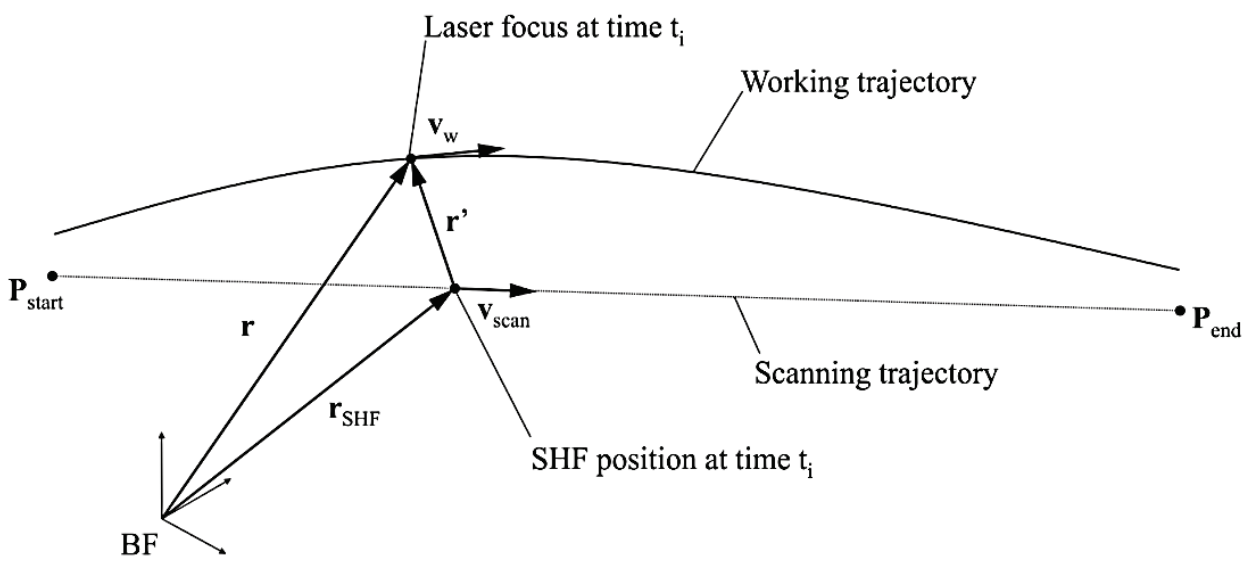

Figure 3 Schematic of the laser focus guiding along the working trajectory as a combination of the scanning-head movement $\left(\boldsymbol{r}_{S H F}\right)$ and the laser-beam deflection ( $\left.\boldsymbol{r}^{\prime}\right)$ 
A working-trajectory interpolation follows in order to ensure a constant working speed $\left|\boldsymbol{v}_{w}\right|$. Fig. 3 shows a situation where the scanning head moves along the line $\overline{\mathrm{P}_{\text {start }} \mathrm{P}_{\text {end }}}$ with a constant scanning speed $\left|\boldsymbol{v}_{\text {scan }}\right|$ and the laser beam follows the working trajectory, also with a constant speed. The differences between the locations of the SHF and the laser beam $\mathbf{r}^{\prime}$ are made by the scanning head. The following procedure is used to calculate the $\mathbf{r}^{\prime}$ coordinates as a function of the robot's movement time:

Travel time of the laser focus along the working trajectory with the constant speed, so-called processing time $\left(t_{\text {proc }}\right)$, is calculated according to the absolute value of $\left|\boldsymbol{v}_{w}\right|$ and the length of the working trajectory $\left(L_{w}\right)$ :

$t_{\text {proc }}=\frac{L_{w}}{\left|v_{w}\right|}$

The speed of the scanning head $\left(\boldsymbol{v}_{\text {scan }}\right)$ is calculated as three-dimensional vector:

$\boldsymbol{v}_{\text {scan }}=\frac{\boldsymbol{P}_{\text {end }}-\boldsymbol{P}_{\text {start }}}{t_{\text {proc }}}$

The working trajectory is then resampled using a linear interpolation in such a way that the consecutive trajectory points $\boldsymbol{r}_{i}$ and $\boldsymbol{r}_{i+1}$ are equidistant in 3D space. Additionally, the distances between the consecutive points are determined by the working speed $\left|\boldsymbol{v}_{w}\right|$ and the time increment $\Delta t$ :

$\Delta r=\left|\boldsymbol{r}_{i+1}-\boldsymbol{r}_{i}\right|=\left|\boldsymbol{v}_{w}\right| \Delta t$

Finally, the points in SHF are calculated according to the known scanning speed $\boldsymbol{v}_{\text {scan }}$, the starting point $\mathrm{P}_{\text {start }}$ and the rotation matrix ${ }_{S H F}^{B F} \boldsymbol{R}$ that describes the rotation between the SHF and the BF:

$\boldsymbol{r}_{i}^{i}=\underset{S H F}{B F} \boldsymbol{R}\left(\boldsymbol{r}_{i}-\boldsymbol{v}_{\text {scan }} \Delta t \cdot i-\boldsymbol{P}_{\text {start }}\right)$

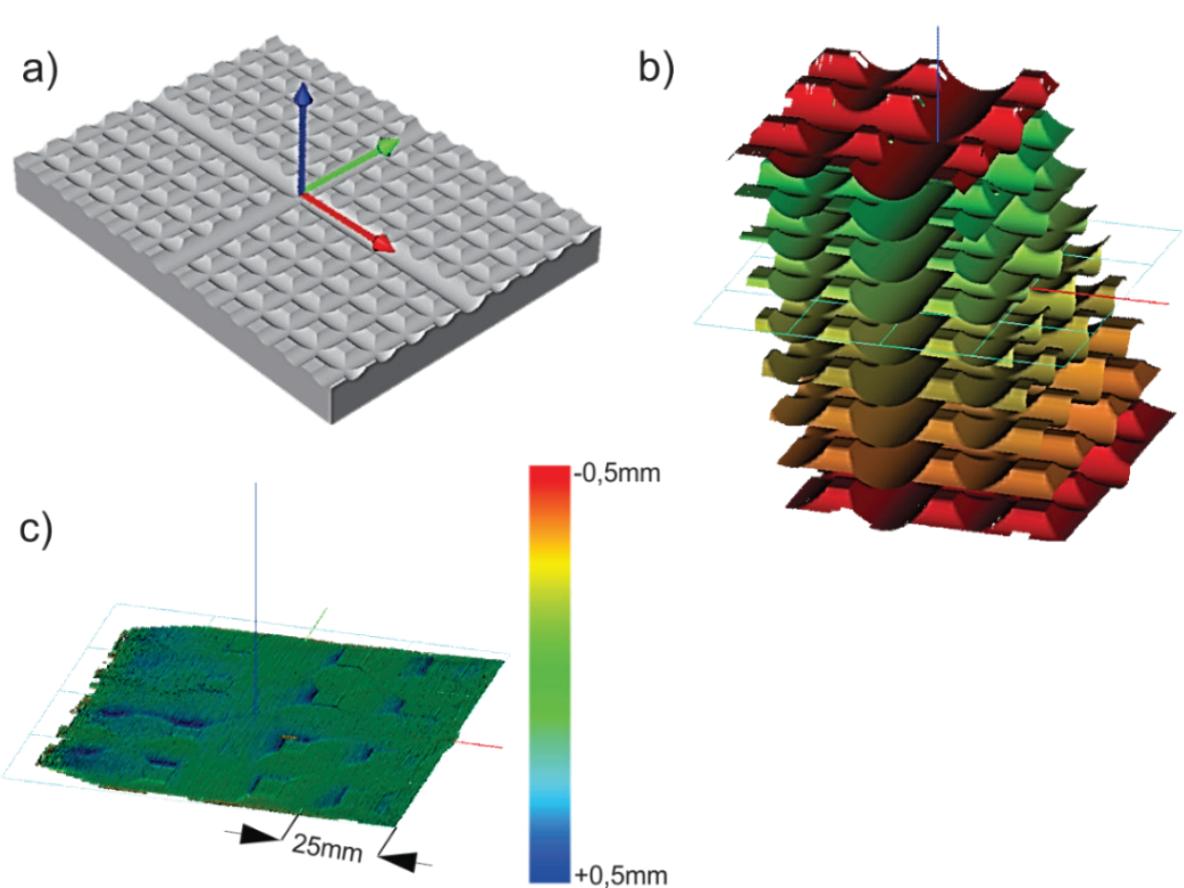

b)
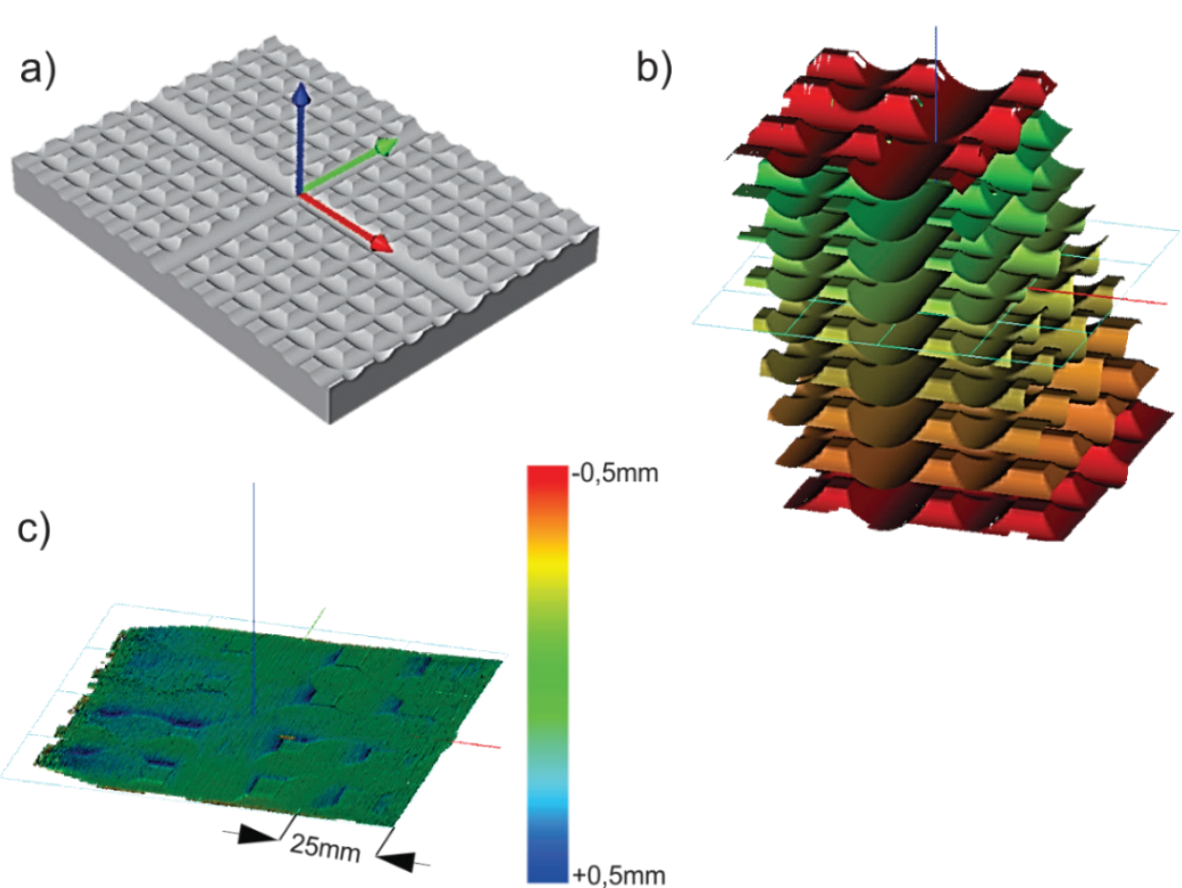

These points are then sent to the scanning head and executed synchronously with the robot's movement. In practice, a preview of the detected working trajectory is first made by the laser's pilot beam for a visual check. If the result is acceptable, the real laser processing proceeds.

\section{System calibration}

Calibration is one of the most important steps when preparing the system for accurate measurements and processing. The following parameters are determined with the calibration: the camera position and orientation relative to the scanning head, the lens distortion and the focal length. All these parameters are needed for an accurate calculation of the measured workpiece in the BF.

The procedure is based on the measurement of a reference, groove-shaped surface, as shown in Fig. 4a. The reference measurement is made at multiple known distances between the scanning head and the reference surface to ensure that the entire measuring range is calibrated. The measured profiles are then transformed into a 3D space using estimated values of the abovementioned parameters. These parameters are then numerically optimized until the minimum deviation (the sum of the squared errors) between the measured profiles and the reference surface is found [25].

An example of a calibration measurement is shown in Fig. $4 \mathrm{~b}$ where the reference surface was measured at 11 height levels with $10 \mathrm{~mm}$ intervals. The standard deviation between the surfaces was $0,15 \mathrm{~mm}$ after optimization and Fig. $4 \mathrm{c}$ shows the difference between the measured points and the reference surface along the $\mathrm{Z}$ axis. It is clear that the differences are equally distributed over the entire region, which indicates that almost all the systematic errors are compensated to the level of the measuring precision.

Figure 4 Calibration measurement of the reference surface (a) at 11 height levels with $10 \mathrm{~mm}$ intervals (b) and the corresponding colour map of the deviations between the measured points and the reference surface (c) 


\section{Results and discussion}

The measurement precision is demonstrated on two characteristic specimens with overlap seam geometry. Fig. 5 shows the measured 3D surfaces of both specimens. The detected working trajectories are marked with dashed lines. The first one is made of stainless-steel plates, where the surface is wavy and the seam has a sinusoidal shape in a perpendicular direction (see Fig. 5a). The specimen has dimensions of $460 \times 200 \times 50 \mathrm{~mm}$ and the plate thickness is $2 \mathrm{~mm}$.

The second workpiece is made of three, flat, rectangular, mild-steel plates, where the smaller two are placed on the larger one (see Fig. 5b). The size of the smaller plates is $66 \times 40 \mathrm{~mm}$, the plate thickness is $1 \mathrm{~mm}$ and the offset between the smaller plates in the perpendicular direction is approximately $16 \mathrm{~mm}$.

The steel plates are made of rolled sheets, where no additional surface treatment was applied. As a result, a combination of specular and diffuse reflections of the pilot laser light was present. The scanning frequency was 40 profiles/s and the scanning width was $100 \mathrm{~mm}$ in all the experiments. The scanning speed was varied in order to show its influence on the detection precision of the working trajectory.

Fig. 6 shows the measuring precision of the wavy specimen. It was measured 21 times between the same starting and final points with a scanning speed of
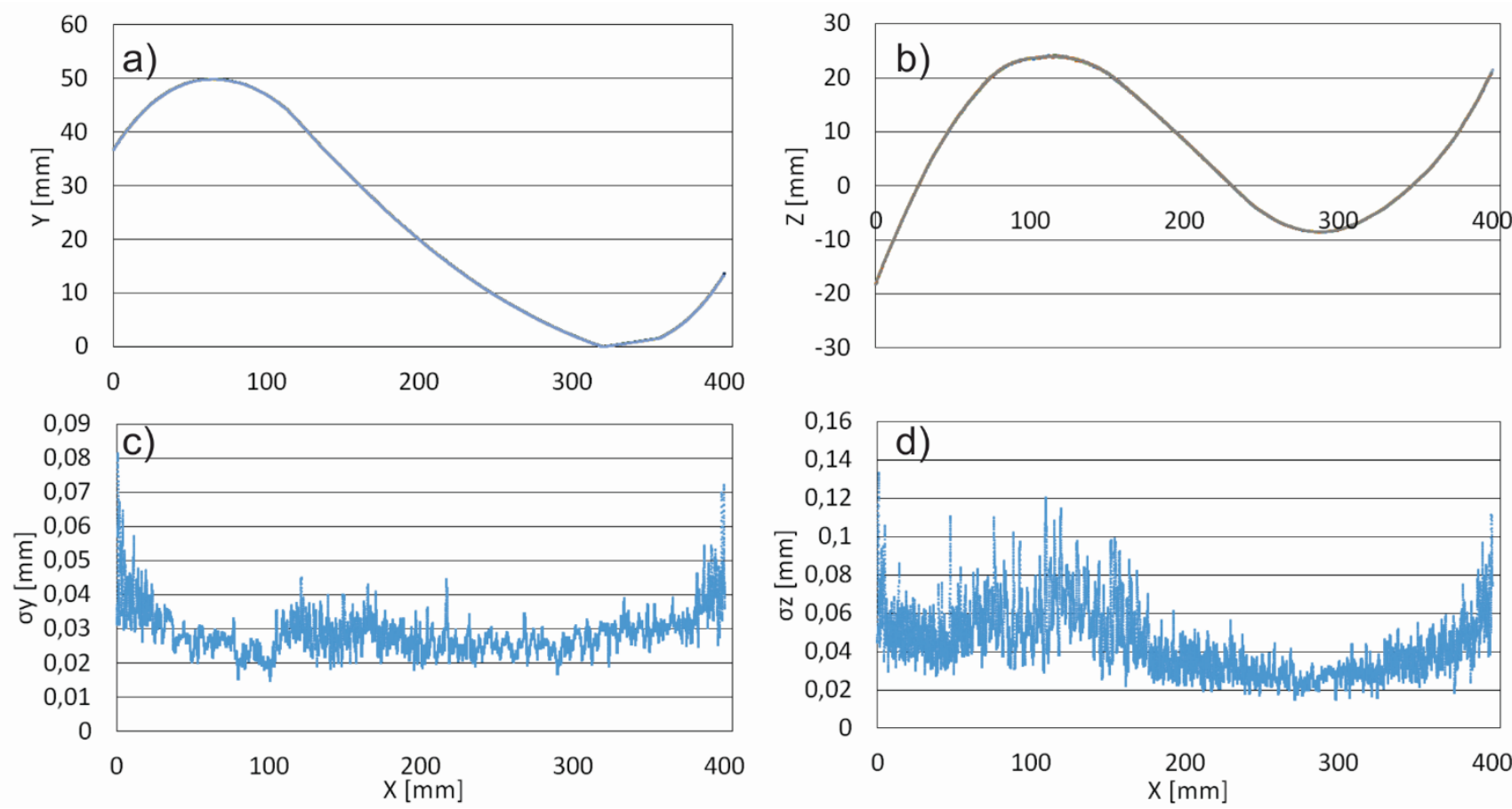

b)

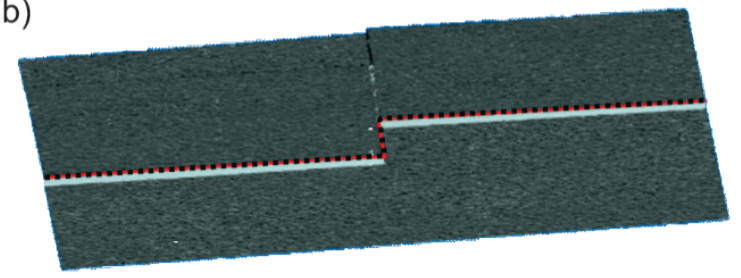

Figure 5 Examples of wavy (a) and step-shaped (b) 3D measured specimens, where dashed line shows the detected working trajectory

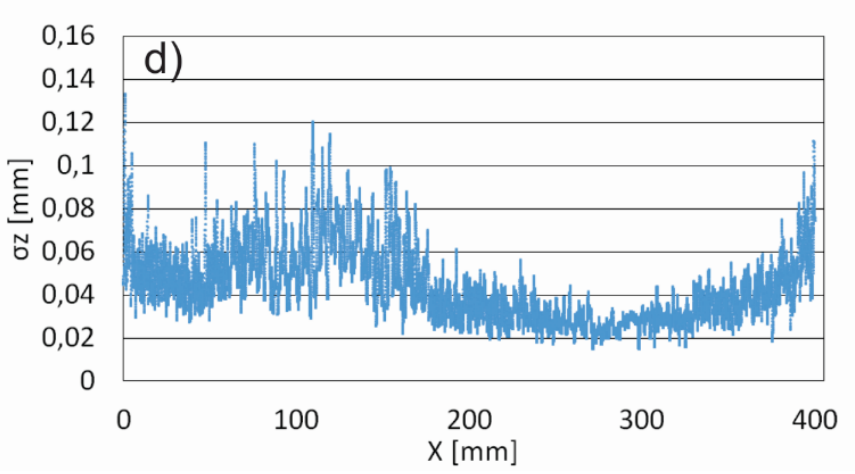

Figure 6 Repeatability $(N=21)$ of sinusoidal trajectory detection. Top left: $X Y$ projection; Top right: $X Z$ projection; Bottom left: standard deviation along the $Y$ axis and Bottom right: standard deviation along the $Z$ axis.

Fig. 7 shows similar results for the step-shaped specimen. As before, the measurements were repeated 21 times between two points with a scanning speed of $8,33 \mathrm{~mm} / \mathrm{s}$. The standard deviations in this case are approximately two times smaller in both directions $\left(\sigma_{Y, \max }<25 \mu \mathrm{m}\right.$ and $\left.\sigma_{Z, \max }<50 \mu \mathrm{m}\right)$. A higher deviation only appears for the step where the scanning precision along the $X$ direction also affects the other two directions.

The dependences of the standard deviations along all three directions versus the scanning speed are shown in Fig. 8. The $\sigma_{Y \text {.mean }}$ and $\sigma_{Z \text {.mean }}$ were calculated as an average of the deviations presented in Fig. $7 \mathrm{c}$ and $7 \mathrm{~d}$, while the $\sigma_{X}$ was calculated as a standard deviation of the step location along the $X$ direction. 

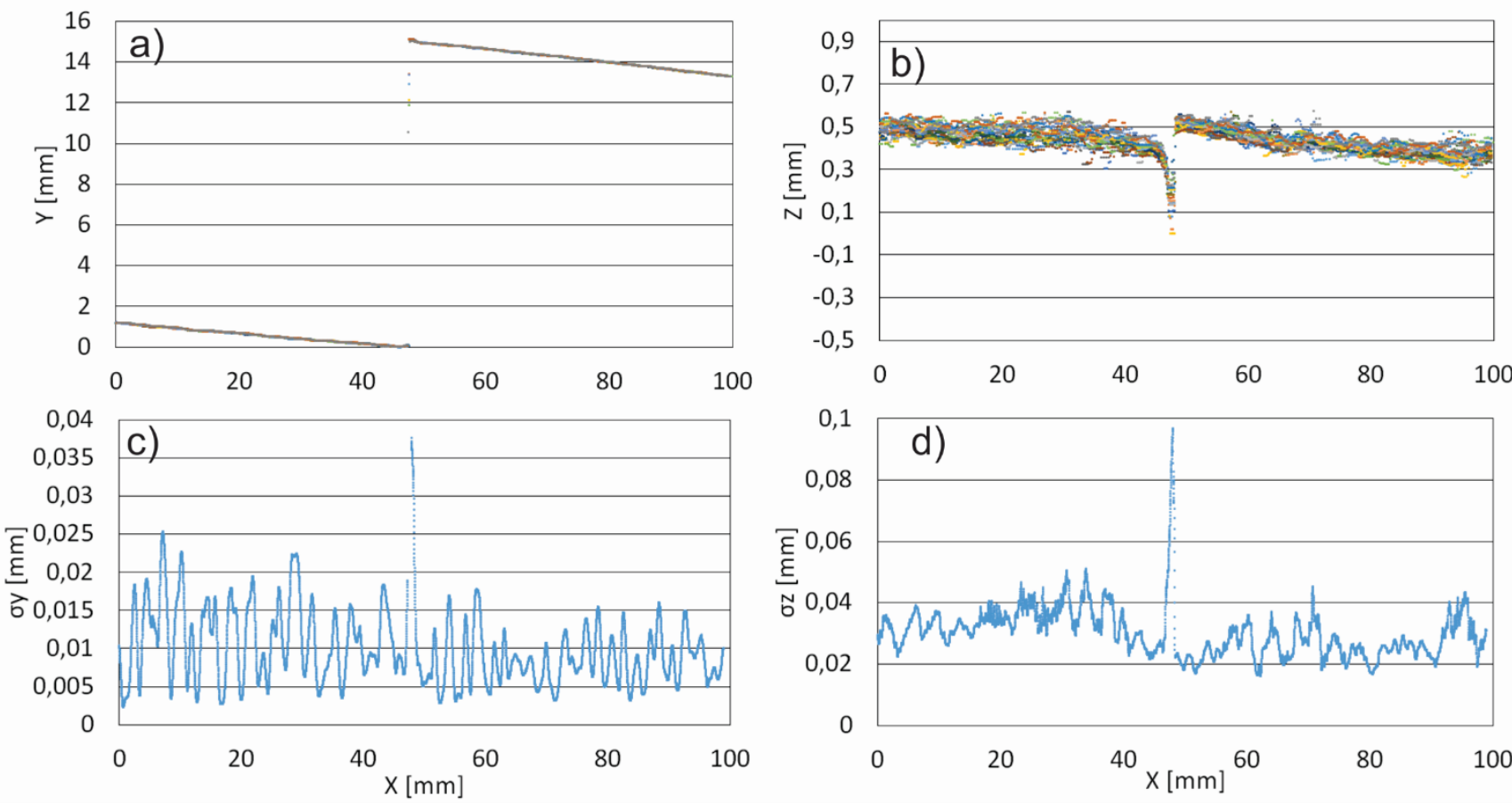

Figure 7 Repeatability $(N=21)$ of the step-shaped trajectory detection. Top left: $X Y$ projection; Top right: $X Z$ projection; Bottom left: standard deviation along the $Y$ axis and Bottom right: standard deviation along the $Z$ axis.

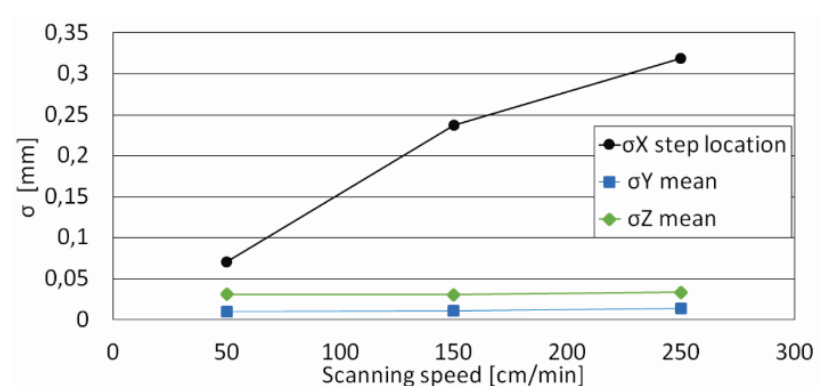

Figure 8 Precision of edge detection versus scanning speed. Measurements were made on a step-shaped specimen.

The scanning speed only has an influence on the precision along the scanning direction (see Fig. 8), which is to be expected, as this increases the distance between the consecutively measured profiles and consequently the scanning resolution. But in the case of a sloping edge (such as the specimen in Fig. 5a) the precision along the scanning direction also affects the precision along the other two directions.

The above results show that the system measures the workpiece with an appropriate precision for successful automatic contour detection in $3 \mathrm{D}$ space. Automatic 3D teaching, which includes the manual determination of the start and end points, the 3D measurement $(500 \mathrm{~mm}$ scan length with a scanning speed of $500 \mathrm{~mm} / \mathrm{min}$ ) and the detection of the working trajectory, typically lasts less than 2 minutes, which is more than 30-times faster than the manual teaching procedure (assuming a similar shape to the specimen in Fig. 5a).

Compared to the reduced teaching time, the improved measuring precision is even more important. The standard deviation in the lateral $\mathrm{Y}$ direction is everywhere less than $70 \mu \mathrm{m}$ in the case of a sinusoidal specimen (see Fig. 6b) and less than $25 \mu \mathrm{m}$ in the case of a step-shaped workpiece (see Fig. 7b). The standard deviation in the vertical direction is approximately 2-times higher: $120 \mu \mathrm{m}$ and $50 \mu \mathrm{m}$ for the sinusoidal and step-shaped workpieces, respectively. The greater deviations in the case of the sinusoidal specimen are primarily attributed to the out-of-focus measuring positions and to the specular reflection of the pilot laser into the camera for some regions of the specimen. Fig. 6 confirms this since the deviation along the $Z$ direction is greater in the lower areas and the deviation along the $Y$ direction is greater for the starting and end regions where the specular reflection is directed into the camera.

Comparing the results with the precision of a visual edge determination, the proposed system is more than 10times better, since the standard deviations of a visual determination are approximately $\pm 0,15 \mathrm{~mm}$ and $\pm 1,5 \mathrm{~mm}$ in the lateral and vertical directions, respectively. According to reference [15] the visual precision is mainly determined by the resolution of the human eye, the diameter of the pilot laser beam and the Rayleigh length of the pilot beam. This is in good agreement with the actual data (the resolution of the human eye is approximately $0,2 \mathrm{~mm}$, the pilot beam diameter is $0,1 \mathrm{~mm}$ and its Rayleigh length is $3 \mathrm{~mm}$.

\section{Conclusions}

An innovative system for the automatic 3D teaching of remote laser processing was developed. The teaching is based on 3D measurement of a workpiece with lasertriangulation principle where the laser light plane is generated with the scanning head by the rapid deflection of the laser pilot beam. The 3D working trajectories is detected from measured surface with a precision better than $70 \mu \mathrm{m}$ along the $Y$ direction and better than $120 \mu \mathrm{m}$ along the $Z$ direction at measuring ranges of $100 \times 100$ $\mathrm{mm}$. The precision along the scanning direction depends on the scanning speed, which is $0,08 \mathrm{~mm}$ at $8,33 \mathrm{~mm} / \mathrm{s}$.

The teaching time is more than 30-times shorter, compared to the visual procedure. Therefore, such a system enables a large cost reduction in modern 
production lines that have permanent changes in product geometries and functionalities. With further software development the system could also be used for the control of the workpiece shape and integrity before and after the laser processing in order to increase product quality.

\section{Acknowledgments}

We would like to thank Yaskawa Slovenia for supplying their commercially available robotic system for remote laser welding applications. The authors acknowledge the financial support from the state budget by the Slovenian Research Agency (Programmes No. P20392 and P2-0270).

\section{References}

[1] Steen, W. M.; Mazumder, J. Laser Material Processing. London: Springer London, 2010. DOI: 10.1007/978-1-84996062-5

[2] Majumdar, J. D.; Manna, I. Eds., Laser-Assisted Fabrication of Materials, vol. 161. Berlin, Heidelberg: Springer Berlin Heidelberg, 2013.

[3] Katayama, S. Handbook of Laser Welding Technologies. Elsevier, 2013. DOI: 10.1533/9780857098771

[4] Hock, K.; Adelmann, B.; Hellmann, R. Comparative Study of Remote Fiber Laser and Water-Jet Guided Laser Cutting of Thin Metal Sheets. // Phys. Procedia. 39, (2012), pp. 225-231. DOI: 10.1016/j.phpro.2012.10.033

[5] Cajal, C.; Santolaria, J.; Samper, D.; Garrido, A. Simulation of Laser Triangulation Sensors Scanning for Design and Evaluation Purposes. // International Journal of Simulation Modelling. 14, 2(2015), pp. 250-264. DOI: 10.2507/IJSIMM14(2)6.296

[6] Mahmoud, E. R. I. Characterizations of 304 stainless steel laser cladded with titanium carbide particles. // Advances in Production Engineering \& Management. 10, 3(2015), pp. 115-124, DOI: 10.14743/apem2015.3.196

[7] Tahmouch, G.; Meyrueis, P.; Grandjean, P. Cutting by a high power laser at a long distance without an assist gas for dismantling. // Opt. Laser Technol. 29, 6(1997), pp. 307 315. DOI: 10.1016/S0030-3992(97)00023-6

[8] Kim, S.; Lee, W.; Kim, D. One-Step Distortion Simulation of Pulsed Laser Welding with Multi-Physics Information. // International Journal of Simulation Modelling. 14, 1(2015), pp. 85-97. DOI: 10.2507/IJSIMM14(1)8.291

[9] Lee, D.; Patwa, R.; Herfurth, H.; Mazumder, J. High speed remote laser cutting of electrodes for lithium-ion batteries: Anode. // J. Power Sources. 240, (2013), pp. 368-380. DOI: 10.1016/j.jpowsour.2012.10.096

[10] El-Labban, H. F.; Mahmoud, E. R. I.; Al-Wadai, H. Laser cladding of Ti-6Al-4V alloy with vanadium carbide particles. // Advances in Production Engineering \& Management. 9, 4(2014), pp. 159-167. DOl: 10.14743/apem2014.4.184

[11] Zaeh, M. F.; Moesl, J.; Musiol, J.; Oefele, F. Material processing with remote technology revolution or evolution? // Phys. Procedia. 5, Part A, (2010), pp. 19-33.

[12] LIA Handbook of Laser Materials Processing | John F. Ready | Springer.

[13] Quintino, L.; Costa, A.; Miranda, R.; Yapp, D.; Kumar, V.; Kong, C. J. Welding with high power fiber lasers - A preliminary study. // Mater. Des. 28, 4(2007), pp. 12311237. DOI: $10.1016 / \mathrm{j}$. matdes.2006.01.009

[14] Kratky, A.; Schuöcker, D.; Liedl, G. Processing with kW fibre lasers: advantages and limits. 2008, pp. 71311X$71311 \mathrm{X}-12$.
[15] Gåsvik, K. J. Optical Metrology. Chichester, UK: John Wiley \& Sons, Ltd, 2002. DOI: 10.1002/0470855606

[16] Malamas, E. N.; Petrakis, E. G.; Zervakis, M.; Petit, L.; Legat, J.-D. A survey on industrial vision systems, applications and tools. // Image Vis. Comput. 21, 2(2003), pp. 171-188. DOI: 10.1016/S0262-8856(02)00152-X

[17] Poss, M. G.; Ransom, L. T. Remote laser welding. // US20140175068 A1, 26-Jun-2014.

[18] Jeng, J. Y.; Mau, T. F.; Leu, S. M. Gap Inspection and Alignment Using a Vision Technique for Laser Butt Joint Welding. // Int. J. Adv. Manuf. Technol. 16, 3(2000), pp. 212-216. DOI: $10.1007 / \mathrm{s} 001700050029$

[19] Huissoon, J. P. Robotic laser welding: seam sensor and laser focal frame registration. // Robotica. 20, 3(2002), pp. 261-268. DOI: $10.1017 /$ S0263574701003988

[20] Kosler, H.; Pavlovcic, U.; Jezersek, M.; Mozina, J. Adaptive Robotic Deburring of Die-Cast Parts with Position and Orientation Measurements Using a 3D LaserTriangulation Sensor. // Strojniski vestnik - Journal of Mechanical Engineering. 62, 4(2016), pp. 207-212. DOI: 10.5545/sv-jme.2015.3227

[21] Novak, B.; Babnik, A.; Mozina, J.; Jezersek, M. ThreeDimensional Foot Scanning System with a Rotational Laser-Based Measuring Head. // Strojniski vestnik - Journal of Mechanical Engineering. 60, 11(2014), pp. 685-693. DOI: $10.5545 /$ sv-jme.2014.1950

[22] Regaard, B.; Kaierle, S.; Poprawe, R. Seam-tracking for high precision laser welding applications-Methods, restrictions and enhanced concepts. // J. Laser Appl. 21, 4(2009), p. 183. DOI: 10.2351/1.3267476

[23] Dorsch, F.; Braun, H.; Keßler, S.; Magg, W.; Pfitzner, D.; Plaßwich, S. Process Sensor Systems for Laser Beam Welding. // Laser Tech. J. 9, 3(2012), pp. 24-28. DOl: 10.1002/latj.201290033

[24] Diaci, J.; Bračun, D.; Gorkič, A.; Možina, J. Rapid and flexible laser marking and engraving of tilted and curved surfaces. // Opt. Lasers Eng. 49, 2(2011), pp. 195-199. DOI: 10.1016/j.optlaseng.2010.09.003

[25] Jezeršek, M. High-speed measurement of foot shape based on multiple-laser-plane triangulation. // Opt. Eng. 48, 11(2009), p. 113604. DOI: 10.1117/1.3265522

[26] Chugani, M. L.; Samant, A. R.; Cerna, M. LabVIEW Signal Processing. Pearson Education, 1998.

\section{Authors' addresses}

Assoc. Prof. Matija Jezeršek, PhD

University of Ljubljana,

Faculty of Mechanical Engineering,

Aščkerčeva 6, 1000 Ljubljana, Slovenia

E-mail: matija.jezersek@fs.uni-lj.si

Matjaž Kos B.Sc.

University of Ljubljana,

Faculty of Mechanical Engineering,

Aščkerčeva 6, 1000 Ljubljana, Slovenia

E-mail: matjaz.kos@fs.uni-lj.si

Hubert Kosler, B.Sc.

Yaskawa Slovenija,

Lepovče 23, 1310 Ribnica, Slovenia

E-mail: hubert.kosler@motoman.si

Prof. Janez, Možina, PhD

University of Ljubljana,

Faculty of Mechanical Engineering,

Aščkerčeva 6, 1000 Ljubljana, Slovenia

E-mail: janez.mozina@fs.uni-lj.si 